\title{
Robot-assisted adrenalectomy: state of the art
}

\author{
Gabriele Materazzi ${ }^{1}\left[\right.$ [ Leonardo Rossi ${ }^{1}$
}

Received: 27 May 2020 / Accepted: 26 October 2020 / Published online: 11 November 2020

(c) The Author(s) 2020

\begin{abstract}
Currently, laparoscopic adrenalectomy is worldwide considered the gold standard technique. Both transperitoneal and retroperitoneal approaches have proved their efficacy with excellent outcomes. Since the introduction of da Vinci System (Intuitive Surgical, Sunnyvale, CA), robotic surgery has made many steps forward gaining progressively more diffusion in the field of general and endocrine surgery. The robotic technique offers advantages to overcome some laparoscopic shortcomings (rigid instruments, loss of 3D vision, unstable camera). Indeed, the robotic system is provided of stereoscopic 3D-magnified vision, additional degree of freedom, tremor-filtering technology and a stable camera. Recently, several case series have demonstrated the feasibility and the safety of robot-assisted adrenalectomy in high-volume centers with outcomes comparable to laparoscopic adrenalectomy. Notwithstanding, the technical advantages of the robotic system have not yet demonstrated significant improvements in terms of outcomes to undermine laparoscopic adrenalectomy. Moreover, robotic adrenalectomy harbor inherits drawbacks, such as longer operative time and elevated costs, that limit its use. In particular, the high cost associated with the use of the robotic system is primarily related to the purchase and the maintenance of the unit, the high instruments cost and the longer operative time. Notably, these aspects make robotic adrenalectomy up to 2.3 times more costly than laparoscopic adrenalectomy. This literature review summarizes the current available studies and provides an overview about the robotic scenario including applicability, technical details and surgical outcomes.
\end{abstract}

Keywords Robotic $\cdot$ Adrenalectomy $\cdot$ Adrenal gland $\cdot$ Laparoscopic $\cdot$ Retroperitoneal

\section{Introduction}

The first successful laparoscopic adrenalectomy (LA) was described by Gagner et al. in 1992 [1]. Although initially adopted for the management of small benign lesions, currently LA is worldwide considered the gold standard technique for the treatment of functional and non-functional adrenal lesions with reported masses up to $11-12 \mathrm{~cm}$ in size [2-4]. LA has proved to be safe and should be preferred to open adrenalectomy due to shorter length hospital stay, lower blood loss and equivalent morbidity, except for selected cases, such as malignant tumors potentially

Gabriele Materazzi

gabriele.materazzi@unipi.it

Leonardo Rossi

leonardros@libero.it

1 Department of Surgical, Medical and Molecular Pathology and Critical Area, Endocrine Surgery Unit, University of Pisa, Pisa Hospital, Via Paradisa 2, Edificio $30 \mathrm{~J}$, 56100 Pisa, Italy infiltrating surrounding organs [4]. Nonetheless, recently the frequency of minimally invasive surgery for adrenocortical carcinoma is increasing although further studies are needed to define its role in the treatment of malignancy [5, 6]. Further, the superiority of LA over the open approach was sustained even for benefits derived from a reduced postoperative pain and wound complications and better cosmesis [7].

Additionally, a retroperitoneoscopic technique with the patient placed in prone position was proposed as alternative approach and gained popularity, thanks to the excellent outcomes demonstrated by Walz et al. [8]. An important benefit of the posterior approach is the direct access to the operative field avoiding the need for mobilization of adjacent structures [9]. Further, the retroperiteoscopic technique reduces the risks of complications associated with entering in the peritoneal cavity and displayed some technical benefits for patients with bilateral adrenal lesions or in patients prior underwent abdominal surgery with potential adherences [10]. On the other hand, some limitations were represented by the narrow working space, which could collapse in case 
of excessive suction, close position of the trocar and reduced angulation of the rigid laparoscopic instrument [9].

After the approval of the Robotic system for the surgical scenario, it has gained progressively more diffusion. First robotic-assisted adrenalectomy (RA) was performed by Piazza et al. in 1999 [11] for a patient with right adrenocortical adenoma using the ZEUS AESOP 2000.

Since then, many steps forward have been made and with the introduction of da Vinci System (Intuitive Surgical, Sunnyvale, CA); the robot-assisted adrenalectomy has received so much attention that has been added to surgical options, although LA still remains the gold standard technique.

However, the robotic technique offers advantages to overcome some laparoscopic shortcomings (rigid instruments, loss of 3D vision, unstable camera). Indeed, the robotic system is provided of stereoscopic 3D-magnified vision, additional degree of freedom by means of multi-articulated robotic arms with Endowrist technology, and a stable camera. Further, the natural hand tremor is eliminated and even the position is made more ergonomic, thanks to a comfortable sitting [12].

Despite these technical advantages, RA has not yet demonstrated significant improvements in terms of outcomes to undermine LA and consequently concern about robotic system has raised. First, even for experienced laparoscopic surgeons, a significant learning curve is needed (about 20 cases) to obtain results comparable to the standard [13]. Moreover, due to the additional steps required, such as the docking of the robotic tower, a prolonged operative time is acknowledged $[12,14]$. Last but not least, the major drawback of the robotic surgery is represented by the elevated costs of the purchase and for the maintenance of the unit $[15,16]$.

The present literature review summarizes the current available studies and provides an overview about the robotic scenario including applicability, technical details and surgical outcomes.

\section{Surgical technique}

\section{Transperitoneal approach}

The patient is placed in lateral decubitus position on the opposite side of adrenal pathology. After the pneumoperitoneum is established, three to four robotic ports (on the right side an additional trocar for liver retraction is required) are generally placed two fingerbreadths below the costal margin. An optional first assistant port placed near the rectus muscle border is sometimes necessary for retraction or suction [17].

Docking of the robotic system and connection of the robotic arms.

On the right side, after insertion of the robotic instruments, a liver retractor is introduced through the medial port by the assistant to provide a gentle medial traction on the underside of the liver to provide exposure of the retroperitoneum.

The right hepatic triangular ligament is dissected and subsequently the right hepatic lobe is freed from the diaphragm. Care is taken not to proceed too far medially and injury the right hepatic vein. The retroperitoneum is incised near the border of the inferior vena cava and the adrenal vein is identified, closed and divided. Accurate dissection in this area is of paramount importance as bleeding from the cava can be significant. The peritoneal layer overlying the adrenal gland is then grasped and used as a handle to provide tension in the upward direction. Approaching from the inferior aspect, the dissection proceeds in the relatively avascular plane beneath the adrenal gland until its complete mobilization. Once the specimen is freed from its remaining attachments, it is removed by means of an endocatch bag through an enlarged trocar port [17].

On the left side, first step consists in dissecting of the spleno-colic ligament. Subsequently, the colon in mobilized caudally and the spleen medially. Caution should be used when retracting the spleen due to the lack of haptic feedback with the robot. Mobilization of the spleen continues medially until the spleen will lie under its own weight. Often, when progressing through this avascular plane, the tail of the pancreas and splenic artery are encountered: these structures may need to be gently dissected free and mobilized in continuity with the spleen to allow adequate exposure to the adrenal gland. To obtain an optimal access to the adrenal area, dissection is continued up until the diaphragm and the great curvature of the stomach comes into view. Dissection along the medial plane in the groove between the adrenal gland and the pancreas can help to isolate the area of the adrenal vein. Hence, the adrenal vein is closed and divided and the operation proceeds following the same steps of contralateral procedure [17].

\section{Retroperitoneal approach}

The patient is placed on a prone jackknife position on a Wilson frame. The initial entry to the Gerota's space is obtained through a $12-15 \mathrm{~mm}$ incision at the end of the tip of the 12th rib using an optical trocar. The space is initially created using a dissecting balloon or with digital exploration. Two to three additional 8- or 12-mm trocars are also inserted, under the direction of a finger place in the retroperitoneum, $1-2 \mathrm{~cm}$ apart from the tip of the ribs to prevent subcostal nerve injuries and in a position which avoids collision $[9,18]$.

The operating space is developed by insufflating with carbon dioxide to a pressure between 15 and $24 \mathrm{~mm} \mathrm{Hg}$. In general, lower pressures are initially used and increased only high enough to provide an adequate operative working field. 
Docking of the robotic system and connection of the robotic arms. The dissection begun using the upper pole of the kidney as the initial anatomic landmark. The adrenal vein is identified and early divided.

A careful blunt retraction of the adrenal gland can be performed to dissect the surrounding fat and eventual attachments. Once dissection is completed, the specimen is removed by means of an endocatch bag through a trocar port $[9,18]$.

\section{Outcomes}

\section{Complications and conversion rate}

To evaluate the safety of a novel technique, it is essential to analyze the complications and conversion rate and to compare them with those of alternative techniques.

Although data reported in literature are not homogeneous and the results vary widely due to lacking in many studies of a classification for severity of complication, and since not always the distinction between intra-operative and postoperative complication is clarified, overall, RA is reported to be safe with a low complications rate [4, 14]. Further, the majority of postoperative morbidity included Clavien 1 and 2 complications, whereas severe complications leading to reoperation are unusual [7].

Taking into consideration studies with more than 5 patients, morbidity varied from 0 to $27.2 \%$ (see Table 1 ). In a recent large case series of more than 300 patients [19], it has been reported a post-operative complication rate of 9.2\%; reoperations for severe complications (Clavien $>3 b$ ) were required in only $1 \%$ of cases. These data are substantially superimposable to whom reported by large series of LA [20-22].

Moreover, Greilsamer et al. [19]reported four independent factors for intra-operative and post-operative complications: history of previous ipsilateral surgical procedure, tumor size, patient's age, and need of conversion. In particular, regarding previous abdominal surgery, this datum is in contrast with those reported by a study conducted by Morris et al. [20], which investigates the influence of surgical history on complication rate of LA, without finding any significant association.

The safety of RA is also supported by several meta-analysis which compare the complications and the mortality rate of RA and LA without reporting any significant difference between these two minimally invasive techniques $[4,12,14$, 23, 24].

Worth to be underlined, on the basis of our literature review, robot-assisted adrenalectomy did not harbor any technique specific complication [24-26].
Overall, analyzing data reported in literature, we can extrapolate that RA and LA have similar results in terms of complications and mortality and the incidences of these appear to be mostly related to the pathology or to pre-existent clinical conditions of the patient, rather than to the technique itself, which achieved comparable outcomes [10, 14, 27].

With regard of conversion rate, our review reported values ranging from 0 to $40 \%$ (see Table 1). The highest conversion rate was of $40 \%$ derived from the first randomized controlled study by Morino et al. [28]. The reasons of conversion were malposition of robotic trocars, prolonged operative time and difficulties to obtain accurate hemostasis. In particular, this last observation realistically was related to the initial lack of advanced energy source with typical use of monopolar scissor or bipolar forceps [29]. Accordingly, excluding this study, the higher conversion rate dropped to $16.5 \%$ (see Table 1). Other reported reasons of conversion were local adherence of the tumor to the surrounding organs, technical difficulties and intraoperative bleeding [7]. As a consequence, in some cases, dissection and hemostasis became challenging to manage, leading the surgeon to convert to conventional laparoscopy or open surgery [14]. Furthermore, as reported, the learning curve plays a role in determining the conversion rate [25, 28].

In a recent review on national inpatient sample [16], the authors reported a conversion rate of $\mathrm{RA}<2 \%$, a comparable value to that of LA. In agreement with this, several metaanalysis reported similar data between RA and LA regarding the complication rate [12, 14, 23, 24, 29].

Undoubtedly, the Robotic System harbors potential advantages to the surgeon, such as stereoscopic magnified$3 \mathrm{D}$ vision, increased instrument dexterity, additional degrees of freedom and more ergonomics, but to date, such features have not evidenced to get superiority compared to LA which remains the current gold standard technique.

These data prompt that RA is feasible, effective and safe but have not shown any advantages in terms of outcomes. Moreover, some concerns still remain regarding the loss of tactile feedback, which is reported to be attributable to the incidence of some complications at the beginning of the experience [30].

\section{Operative time}

Regarding operative times (OT), there is a wide range reported by several studies which varies from 89 to $215 \mathrm{~min}$ (see Table 1) [9, 19].

Many comparative studies reported a significant longer operative times for RA vs LA [10, 26, 28, 31, 32] and these data are further confirmed even by recent meta-analysis [12, 14]. Notwithstanding casuistries, with no statistical significant difference in OT between RA and LA, are described 


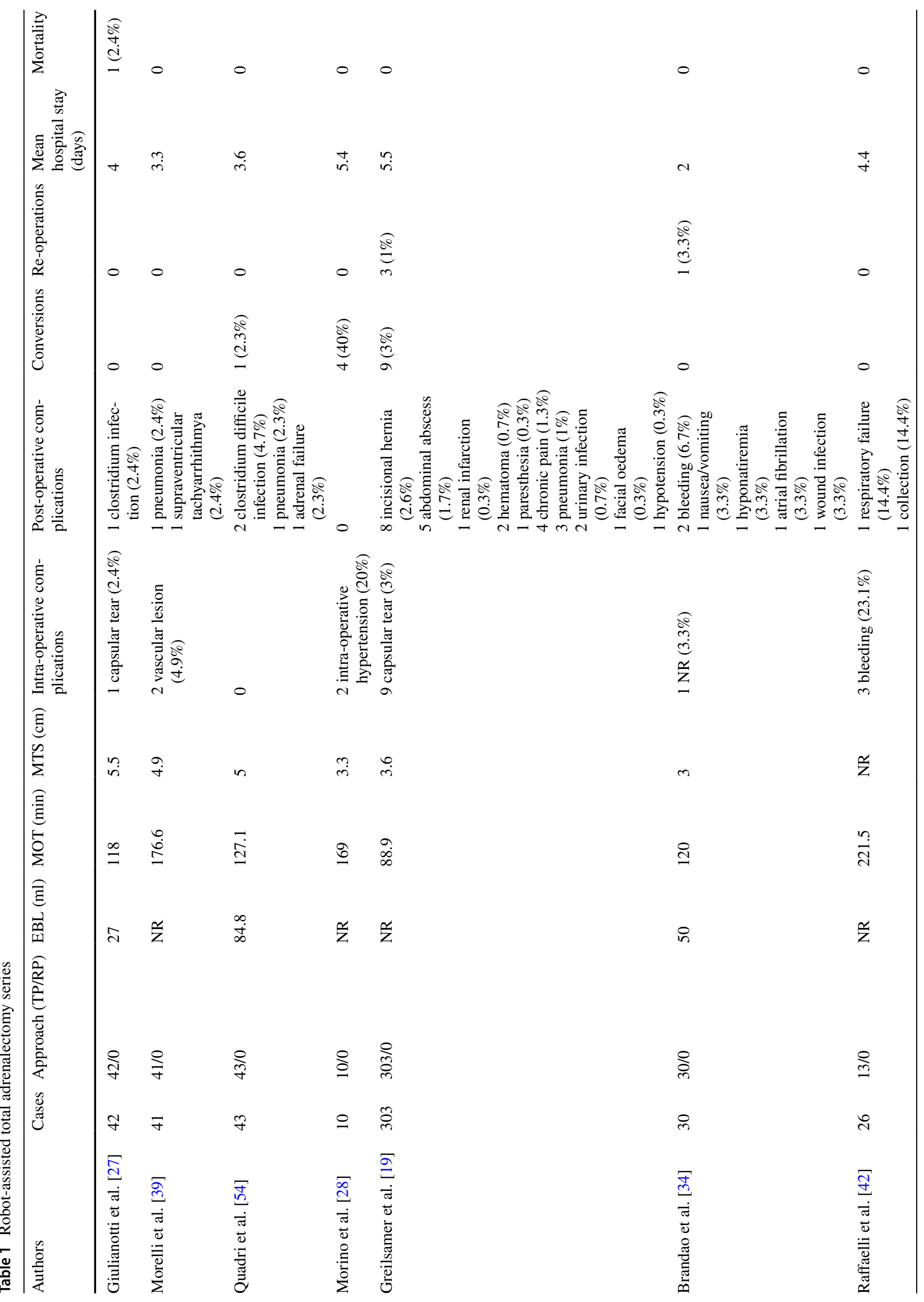




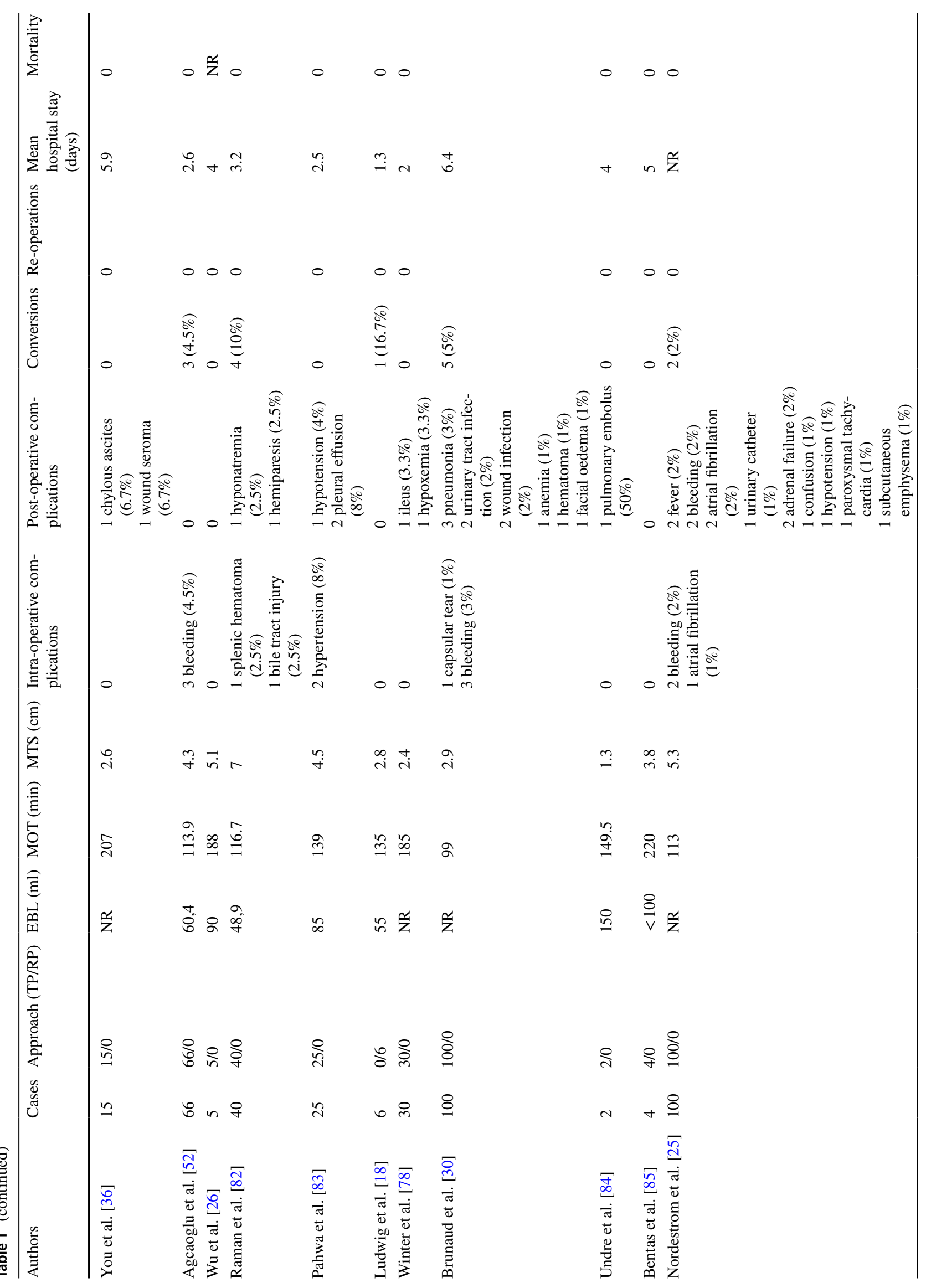




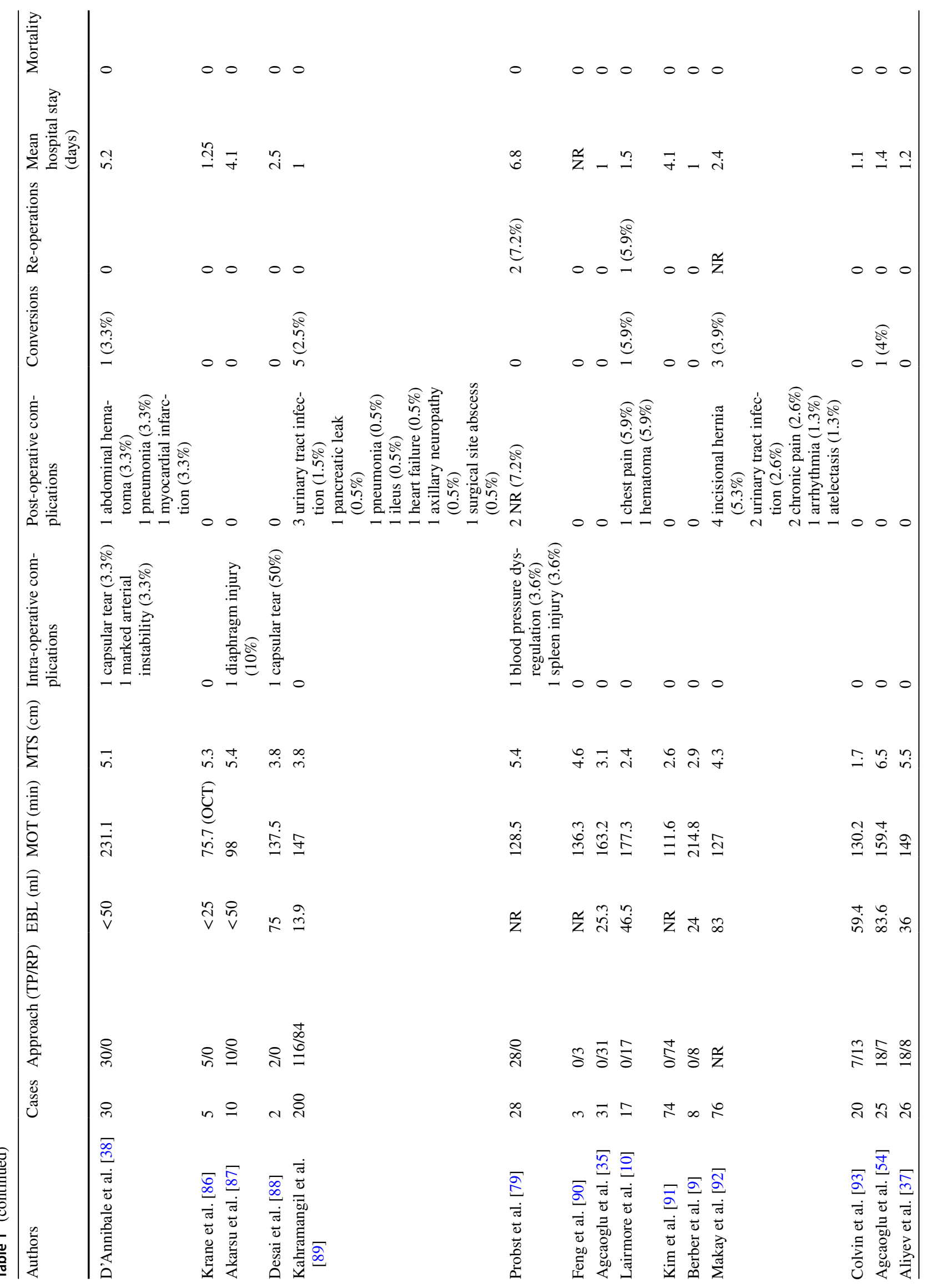


too [33-36], the heterogeneity of the results risks to weaken the strength of the reported data. Indeed, the definition of "operative time" is not clarified in large part of the studies, which not defining the starting and the ending of the procedure and, furthermore, only few case series reported separately the docking/set-up time [26, 30, 35, 37]. Moreover, inclusion of transperitoneal along with retroperitoneal approach in the analysis may have further confounded the overall exits. Intuitively, RA harbors a potentially longer operative time attributed to the docking of the robot, the camera calibration, the connection of the robotic arms to the robotic trocar as well as the undocking of the robotic system $[12,23]$. These additional steps increase the mean overall "real" operative time by 15-40 min and can be as long as $1 \mathrm{~h}$ at the beginning of the experience [7]. Moreover, Agcaoglu et al. [35] reported that the transport of the robotic unit to the operating room, system start-up, draping of the robotic arms and calibrating the robotic camera can take up to 20-25 min.

Additionally, it is reported by several studies that the surgeon's experience has an impact on influencing the OT [19, 30, 35, 38]. Indeed, Greilsamer et al. [19] reported a significant decrease of the operating time between the first 100 RA and the last 100 RA. Similarly, Agcaoglu et al. [35] reported a significant reduction in the operative time after the 10th RA with retroperitoneal approach, reaching lower values than the laparoscopic counterpart and shortening the skin-to-skin operative time by $28 \mathrm{~min}$. Similar results were reported by Brunaud et al. [30] and D'Annibale et al. [38], who assumed that the additional time may decrease as more procedure are performed and that the plateau of the learning curve is reached, respectively, after 12 and 20 cases. Therefore, Brunaud et al. [30] reported that surgeon's and first assistant's experiences, as well as tumor size, play a role in determining the OT of RA.

Overall, it seems reasonable that, beyond the learning curve, since the robotic procedure follows the same surgical steps of the laparoscopic one, these two techniques show a similar "surgical time"; notwithstanding, we have to acknowledge that with the use of robotic system, it is mandatory to take into account even the time needed to dock and undock the robotic tower with its arms. Such steps prolong the overall surgical time from 15 to $60 \mathrm{~min}$, depending on the experience of the team [31].

Moreover, our opinion is that hospitals with dedicated robotic-operating rooms and specific equip are advisable to cut down the additional set-up time.

\section{Hospital stay and blood loss}

Of course, one of the most important advantages of minimally invasive approach is the fast recovery and the short hospital stay (HS). These considerations are true even for 
RA: basis on our literature review, HS ranges from 1 to 6.8 days (see Table 1 ).

The length of HS has been evaluated and compared to those of LA in several studies without finding any statistical significant difference $[31,32,34,39,40]$. Anyhow, several meta-analysis reported a shorter hospital stay for RA vs LA $[4,10,12,14,23]$.

Nevertheless, some Authors advocated [41, 42] that the difference in the length of hospitalization could be confounded by many factors and may be not reliable in the comparison between minimally invasive techniques.

Similarly, RA is a safe procedure with a low estimate blood loss (EBL) value (see Table 1). Several case series reported similar EBL values between RA and LA [31, 33, 37]. Consistent with these data, also a recent meta-analysis [12] and a review of a national inpatient sample [16] did not report any significant differences between RA and LA in EBL. Nevertheless, some meta-analysis [4, 14, 29] reported a significant lower EBL in the RA group theoretically attributable to the stereoscopic magnified vision and the more precise dissection. However, worth to focus that the difference, although statistically significant, is not clinically relevant since the gap, as reported in another meta-analysis [43], is very limited $(25 \mathrm{ml})$ and does not influence the patient management or the need of transfusion. According to this, no difference was noted comparing the incidence of blood transfusion between RA and LA [16, 23].

Last but not least, a recent paper by Rothermel et al. [44] reported that blood loss estimations are not a reliable metric to judge surgeons' performance or patient outcomes.

Overall, RA is undoubtedly safe with optimal outcomes in terms of HS and EBL. Anyway, the potential advantage upon LA - the current gold standard technique - is controversial. In particular, a reduction in the length of the HS can be explained only by a minor trauma [45]. Since the surgical steps of RA and LA are superimposable, and considering that often RA requires additional trocar and is performed in similar surgical times, it seems unreasonable expecting difference in terms of HS. As reported by Agrusa et al. [29], the difference could hide operator relating bias explained with the positive expectation from a novel technique and the medical staff focused on the early hospital discharge.

\section{Robot-assisted bilateral adrenalectomy}

Bilateral adrenalectomy (BA) is required in case of recurrent or persistent Cushing disease, in case of primary bilateral adrenal disease or in case of familial syndromes, such as NEM 2, Von Hippel Lindau Syndrome or congenital adrenal hyperplasia [7]. Robotic surgery is particularly endearing in case of bilateral procedure since it offers a finer dissection and a comfortable seat which can be particularly helpful in case of long procedure [42].

Raffaelli et al. [42], in a retrospective multicenter study involving two university third-care referral centers, compared three different technique for BA (laparoscopic transabdominal adrenalectomy, retroperitoneoscopic adrenalectomy, robotassisted transabdominal adrenalectomy). Robot-assisted BA was found to have a statistically significant lower number of drains used and shorter hospital stay. Anyway, as clearly explained by the authors, these findings were likely related to the different management protocols used in different centers. Indeed, in one of the involved centers drains are routinely positioned, whereas in the other drains are positioned on the basis of surgeon's discretion. Further, in one center, patients referred from distance are kept hospitalized until they are able to maintain oral dose of hydrocortisone and can safely travel considerable distance back home, whereas in the other center, patients unable to be maintained under oral dose of hydrocortisone are referred to the endocrinology unit [42].

Since during transperitoneal, BA patients are positioned in lateral decubitus, one of the main drawbacks for this approach is the time duration needed to re-position the patient between the two sides [7, 42]. As in conventional laparoscopy, this limitation is overcome by means of robot-assisted BA with retroperitoneoscopic approach which enables an effortless transition from one gland to the other avoiding repositioning [23, 46]. Moreover, Taskin et al. [46] reported that in case of bilateral macronodular adrenal hyperplasia, since adrenalectomy in these cases can be challenging due to multiple nests of adrenal tissue, the articulated robotic instrument can make the dissection easier compared to the rigid laparoscopic instrument.

Anyway, to date, consistent data of a potential superiority of the robotic over the laparoscopic technique are lacking. Bilateral laparoscopic adrenalectomy has proven to be feasible and safe by several studies $[47,48]$ and to date, still being the gold standard approach. Overall, the same considerations made for unilateral RA are likely to be valid even for robotic BA.

We believe that the classic retroperitoneoscopic approach has technical advantages in case of BA since it enables to avoid the reposition of the patient leading to shorter operative time with comparable outcomes to transperitoneal approach [48].

Due to the scarcity of comparative papers reported in literature, further studies are required to draw definitive conclusions.

\section{Robot-assisted adrenalectomy in obese patients}

Although the incidence of obesity continues increasing worldwide, the impact of obesity on peri- and post-operative outcomes in patient underwent RA is debatable and available large casuistries are lacking. 
Recently, Maker et al. [49] published a video showing a RA in an obese patient (BMI $36 \mathrm{~kg} / \mathrm{m}^{2}$ ) concluding that this technique is feasible and safe in obese patient with large tumor.

Moreover, some case series [39, 50] reported that obese patients are good candidates for RA. Brunaud et al. [50] reported no difference in terms of operative time between patients with a BMI $>$ or $<$ to $30 \mathrm{~kg} / \mathrm{m}^{2}$ underwent RA, whereas a significant higher operative time was registered for patients $>30 \mathrm{~kg} / \mathrm{m}^{2}$ underwent LA.

Furthermore, Greilsamer et al. [19], in a study involving a large sample of obese patients (82), determined that obesity was not significantly associated with longer operative time or peri-operative complications. Notwithstanding, a recent study by Pedziwiatr et al. [51] conducted on 520 patients underwent LA and subdivided on the basis of BMI in four groups (normal weight; overweight; obese; morbidly obese) reported similar results. Indeed, the authors did not found any statistical significant difference between groups in terms of operative time, complications, conversions and blood loss. The authors concluded that LA is feasible regardless of BMI and that obesity has no influence on short-term outcomes after transperitoneal LA [51].

Additionally, Agcaoglu et al. [52] in a study focused on the evaluation of the impact of BMI on outcomes of RA, observed no statistically significant differences between two groups of patients divided on the basis of BMI (<or $>30 \mathrm{~kg}$ ) $\mathrm{m}^{2}$ ) in terms of operative time, complications, conversions, blood loss and length of hospitalization.

A comparative prospective study on obese patients was performed in 2013 by Aksoy et al. [40]. The authors included in this paper 42 obese patients who underwent RA and 57 obese patients who underwent LA. They found no statistically significant differences between the two groups, concluding that in adrenal surgery, the benefits provided by articulated instruments and 3-D magnified vision proper of the robotic surgery are nullified in obese patients for the difficulties in maintaining exposure and dissection.

In conclusion, peri-operative outcomes in obese patients who underwent RA are still debated and controversial, but we believe that in experienced hands the robotic technique can be performed safely with results comparable to those obtained in non-obese patients. Nonetheless, same outcomes are achievable with LA, which currently remains the gold standard technique.

\section{Robot-assisted adrenalectomy in patients with large tumor}

Minimally invasive resection of large adrenal masses has raised two major concerns: first, the risk of capsular disruption or incomplete removal of an unsuspected malignant tumor with increased risk of recurrence; second, the technical difficulty in dissection due to the large size of the lesion $[41,53]$.

Several studies investigate the feasibility and the safety of minimally invasive adrenalectomy for large tumors [39, 54, 55]. In 2012, Agcaoglu et al. [54] conducted a comparative study between RA and LA performed for large adrenal masses. They found that RA leads to a significantly shorter operative time and hospital stay with a lower rate of conversion to open surgery, and claimed that the robotic approach has become their preferred minimally invasive technique for removing large adrenal masses.

Quadri et al. [55] in a recent study conducted on 43 cases of RA, divided patients on the basis of tumor size $(<$ and $>$ of $5 \mathrm{~cm}$ ) and reported no significant differences in terms of operative time, length of hospital stay, readmission, complications and conversion rate. Extending the size limit to $8 \mathrm{~cm}$, the only statistically significant difference was in terms of higher conversion rate. Anyway, due to the small sample (only six patients), larger studies are needed to better assess differences in peri-operative and post-operative outcomes in tumors $>8 \mathrm{~cm}$ versus $<8 \mathrm{~cm}$.

In a systematic review, Teo et al. [41] concluded that RA is feasible in patient with large tumors and they suggested that the good outcomes obtained with the robotic approach can be due to the articulated wristed instruments and the 3-D magnified vision which enable a faster and more accurate dissection. Moreover, they recommended the transperitoneal approach since the restricted retroperitoneal space can make the dissection challenging with large lesions.

Thompson et al. [56] in an analysis of Swedish database including 659 adrenalectomies (37.9\% were RA) reported that the robotic approach was preferably used in patients with large tumors, suggesting some advantages of the robotic system in these cohort of patients.

Anyway, laparoscopic adrenalectomy for large tumor has previously described to have good outcomes [57]. Conzo et al. [58] in a recent systematic literature review reported that in selected cases LA is feasible and safe even for large masses $(>6 \mathrm{~cm})$ and that the retroperitonescopic approach is demonstrated feasible for tumors up to $8 \mathrm{~cm}$.

In conclusion, our hypothesis is that skilled surgeons can performed safely both LA and RA, in patients with large tumors, with good outcomes. Notwithstanding, it is mandatory to adhere to oncologic principles and we believe that large adrenal lesions should be managed in high-volume centers and that suspected adrenal carcinomas are preferably approached by open technique. Overall, the robotic system shows endearing features for large lesions, but further studies are required for the assessment of its impact on outcomes and to evaluate if these qualities outweigh the burden of the costs. 


\section{Robot-assisted partial adrenalectomy}

Although the standard of care for the major part of adrenal pathologies is total adrenalectomy, there are a few situations in which partial adrenalectomy is an option. Indeed, adrenal-sparing technique plays a role in patients with bilateral adrenal lesions or a mass within a solitary adrenal gland or in patients at the highest risk of developing multiple adrenal tumors, such as in hereditary diseases.

Partial adrenalectomy (PA) has the advantage of preserving adrenocortical function and, if successful, avoiding steroid supplementation [59]. In a literature review, Kaye et al. [60] reported that the number of parenchymasparing adrenalectomy is increasing and surgical outcomes and peri-operative complications are similar to those reported for total adrenalectomy.

Robot-assisted partial adrenalectomy was first described in 2006 by St Julien et al. [61] in a patient with bilateral pheochromocytoma and Von Hippel Lindau disease. The robotic system seems to be well-suitable for this technique since it enables a particularly delicate manipulation, thanks to the articulated wristed arms with multiple degree of freedom and to the 3D-magnified vision.

Several studies reported the feasibility and the effectiveness of robotic-partial adrenalectomy (see Table 2). Recently, Ye et al. [59] reported their experience for partial adrenalectomy with transperitoneal approach on 13 patients with optimal outcomes. Indeed, beyond the good technical results (low operative time and blood loss), they reported no conversions and no post-operative complications. At a median follow-up of 12 months, no patients required steroid replacement and no recurrences occurred [59].

Moreover, Asher and colleagues [62] reported the largest series of 15 cases of PA (on 12 patients). All of the patients were affected by pheochromocytoma. They reported only one conversion and one complication; further, no intra-operative hypertensive or tachyarrhythmics events were registered and after a median follow-up of 17.3 months, there were no recurrences and only one patient with a solitary gland needed steroid replacement. Similarly, other casuistries showed similar results [63-65]. Interestingly, Kohene et al. [66] reported a case of a patient who underwent robot-assisted partial adrenalectomy with retroperitoneoscopic approach.

Simone et al. [64] claimed that the main advantages of robot-assisted partial adrenalectomy are the minimal manipulation of the surrounding adrenal cortex and the preservation of blood supply of the adrenal remnant tissue, steps which are particularly challenging with the laparoscopic approach.

Despite encouraging results, however, only few case series are reported in literature with small samples and

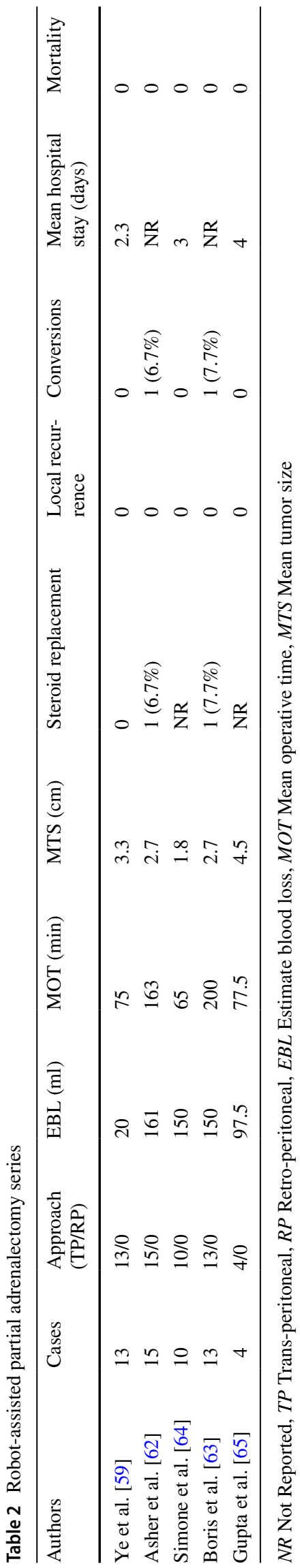


there does not exist any comparative study between robotic- and laparoscopic-PA. Anyway, the robot-assisted PA may offer some technical benefits although further investigations are needed to proper define the role of this approach in adrenal-sparing procedure.

\section{Robot-assisted single-site adrenalectomy}

Recently, laparoendoscopic single-site (LESS) adrenalectomy has been introduced on the basis that with a smaller number of incisions, enhancement of cosmesis and reduction of associated port site complications can be obtained [41]. Further, patients predisposed to a delayed wound healing, such as Cushing's patients, may avoid wound complications [41]. The drawbacks of LESS consist in a smaller distance between instruments and in the loss of their triangulation [41].

Interestingly, Pavan et al. [67] performed a recent retrospective multinational multicenter study including 737 adrenalectomies, $36 \%$ of whom were performed with LESS technique. Moreover, the authors [67] noted that from 2008 to 2013, LESS had the fastest increase in utilization (6\% per year) among the techniques analyzed and that this procedure was mostly performed in Asia and South America.

Both transperitoneal and retroperitoneal approach has been described for Robot-assisted LESS adrenalectomy (see Table 3). Arghami et al. [68] reported a matched-cohort study comparing 16 single-port robot-assisted adrenalectomies with 16 laparoscopic adrenalectomies. They reported the same rate of conversion to open surgery $(6 \%)$ but in the robot-assisted group, $12 \%$ of cases were converted to laparoscopic surgery due to dense inflammatory reaction and to difficulty in visualizing adrenal gland. Further, the same complications rate between the two approaches was described (12\%) and there were no peri-operative deaths in both groups. Moreover, the authors [68] found that patients in the robotic-assisted LESS group had statistically significantly lower narcotic use in the first $24 \mathrm{~h}$ after surgery.

In a study on 33 patients who underwent robot-assisted single site-site adrenalectomy, Lee et al. [69] reported a conversion rate to laparoscopic surgery of $13 \%$ and to open surgery of $6.1 \%$; peri-operative complications rate was $15.8 \%$. In this study [69], it is underlined that that the technical limitations encountered were related to the increased flexibility of the instruments that occurs when they are inserted farther in the trocar. They suggested that this limitation can be outweighed by manipulation of the single-site port to a more cephalad position and with the use of a longer trocar. Furthermore, The authors [69] concluded that Robotassisted LESS is comparable to the others minimally invasive approach in terms of safety and outcomes and it can be

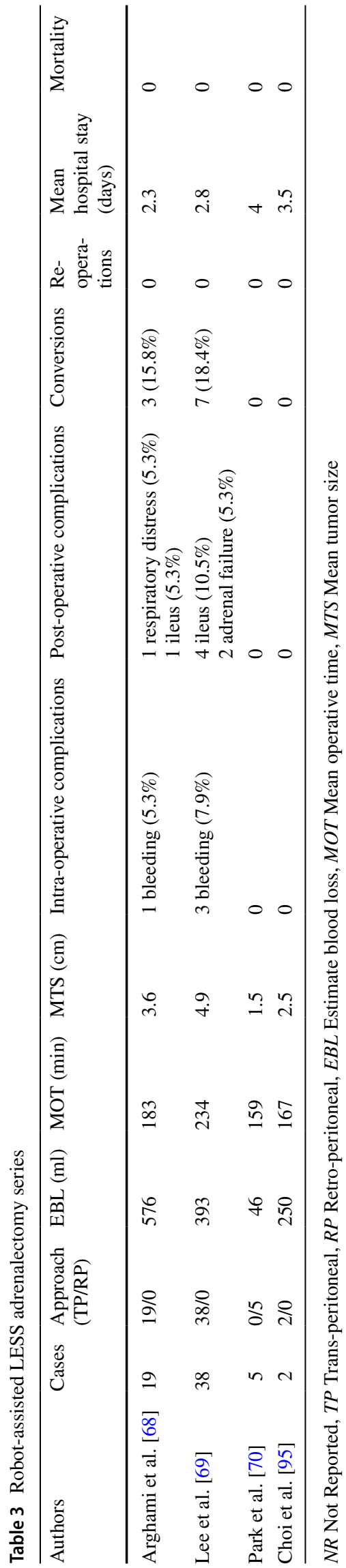


adopted both for non-functional and functional tumors and even in obese patients.

Furthermore, the robotic LESS approach has been performed even with the retroperitoneal access; Park et al. [70] reported their initial experience on five patients with encouraging outcomes (no conversions, no complications). Due to the small operative space, they recommend to start performing robot-assisted LESS with retroperitoneal approach for tumors smaller than $2 \mathrm{~cm}$ in patients with a body mass index lower of $30 \mathrm{~kg} / \mathrm{m}^{2}$ and gradually extending the indications with increasing experience.

Finally, Wang et al. [71] performed a meta-analysis and reported that laparoscopic single-site adrenalectomy appears to be a feasible and safe alternative to conventional LA with a lower post-operative pain, although associated with a longer operative time.

Assumed that safety and effectiveness are key factors in the selection of a technique, the role of robotic system with this approach is still to be defined as large case studies are lacking.

\section{Indocyanine green fluorescence imaging during robotic adrenalectomy}

Endocrine surgery is particularly appropriate for IndoCyanine Green (ICG) fluorescence imaging due to the elevated blood supply of gland parenchyma [72]. ICG fluorescence was first used in humans by Manny et al. [73] in 2013 in a case series of three robot-assisted partial adrenalectomies.

The use of ICG fluorescence enables visual distinction between hyperfluorescent adrenocortical tissue (highly vascular) and hypofluorescent retroperitoneal tissue (poor vascular), making the dissection plan easier to be identified [74]. Furthermore, it resulted helpful in defining the border between tumor and surrounding normal tissue (particularly useful during cortical-sparing adrenalectomy for pheochromocytoma or bilateral procedure) and enables to evaluate the vascularity of the remaining adrenal parenchyma at the end of the dissection [75]. Moreover, the real-time feedback of ICG fluorescence supports to compensate the lack of haptic feedback during RA, traditionally used to determine the margin of resection [74].

Kahramangil et al. [76] in a case series of 100 robotassisted adrenalectomy reported that the exhibition of fluorescence is depending on the histologic origin (cortical versus medullary); in their study, adrenocortical tumors displayed a higher intensity of fluorescence compared with the surrounding retroperitoneal soft tissues, whereas medullary adrenal tumors were non-fluorescent. This feature could be particularly useful when performing cortical-sparing adrenalectomy for familial bilateral pheochromocytoma [72]. Manny et al. [73] hypothesized that the lack of fluorescence of pheochromocytoma could be related to the lower expression of bilitranslocase, an enzyme affecting ICG uptake.

In a case series of ten RA, Sound et al. [77] reported that ICG imaging resulted helpful with the conduct of the operation in eight out of ten procedures. In two cases, ICG imaging did not add any information; one was a patient who underwent right retroperitoneal adrenalectomy where the fluorescence of the liver did not enable any contrast distinction between the adrenal and retroperitoneal tissues, and one was a patient with a $6.5-\mathrm{cm}$ adrenocortical neoplasm where the adrenal mass did not show any fluorescence.

Further, Colvin et al. [72] in a study conducted on 43 robot-assisted adrenalectomy, reported that the distinction of the adrenal tumor's border with use of ICG increases the precision of dissection compared to conventional robotic visualization in about half of cases.

In conclusion, although this new technique does not replace an accurate dissection, the use of ICG fluorescence may be useful for patients requiring partial adrenalectomy to avoid adrenal failure and in refractory cases where it is challenging to resect completely the adrenal parenchyma. The loss of tactile feedback proper of the robotic surgery can be partially compensated with this imaging modality; nevertheless, future researches will investigate the impact of ICG fluorescence on outcomes.

\section{Cost-effectiveness}

One of the most significant concerns about robot-assisted surgery regards its prohibitive costs. The elevated cost associated with robotic surgery is primarily related to the purchase and the maintenance of the unit, the high instruments cost, the use of semi-disposable instruments and the longer operative time [15].

Agcaoglu et al. [35] in a comparative study between posterior retroperitoneal RA vs LA reported that the additional cost of robotic surgery (including robotic instruments, drapes and the annual maintenance fee) is about 900-950 \$ per procedure. Furthermore, Brunaud et al. [30] in a cost evaluation reported that RA is 2.3 times more costly than LA ( $€ 4102$ vs $€ 1799$ ). However, cost reduction can be obtained by means of increasing the number of RA per year and with the depreciation of the robotic system [30, 78]. Indeed, in a German study by Probst et al. [79], the additional cost for using the robotic system was $€ 2288$ per procedure, taking into consideration a center with 150 robotic operations per year; this was calculated considering $€ 400,000$ of depreciation cost per year. Since this fee has to be allocated to all robotic procedures, centers with higher number of robotic operations can benefit of a lower cost burden.

Recently, Feng et al. [80] in a comparative study between RA and LA did not observe significantly differences in terms 
of costs. They suggested that possible ways of lowering costs are limiting unnecessary robotic instruments and energy devices and having an experienced team at the operating table. Anyway, their analysis did not take into account the purchase fee since the decision to buy the robotic system was already made, and this fact weakens a lot their conclusion as the robotic system has a considerable cost (the price ranges from \$1 million to \$2.5 million for each unit) [81].

Overall, the costs represent the major drawback of RA and significant benefits should be demonstrated to justify the use of robotic system for adrenal lesions, even in high-volume centers.

\section{Conclusion}

In conclusion, LA should be considered the gold standard technique for adrenal lesions. Both transabdominal and retroperitoneoscopic technique have proved to be safe and effective and the approach should be chosen on the basis of surgeon's experience. Recently, several case series have demonstrated the feasibility and the safety of robot-assisted adrenalectomy in high-volume centers with outcomes comparable to LA. Overall, the robotic system provides some technical advantages, such as increased dexterity, 3-D magnified vision and tremor-filtering technology, but these benefits do not outweigh the elevated cost and the prolonged operative time. Since adrenalectomy is a demolitive procedure that does not require a reconstructive phase, the increased maneuverability provided by the robotic system seems not to be reflected in substantial benefits in terms of outcomes, whereas the concerns regard this technique persist. Notwithstanding, RA may be theoretically well suited for performing cortical-sparing adrenalectomy since this procedure can take advantage of the better visualization and the increased dexterity to effectively preserving the cortical remnant. Moreover, RA could play a role during complex cases in which a reconstructive phase with fine suture is needed.

Funding Open access funding provided by Università di Pisa within the CRUI-CARE Agreement.. None.

Data availability Available if requested.

\section{Compliance with ethical standards}

Conflict of interest The authors declare that they have no conflicts of interest.

Research involving human partecipants and/or animals No research involving human partecipants and/or animals was conducted for the purpose of this paper.

Informed consent Informed consent was not applicable to this review article
Open Access This article is licensed under a Creative Commons Attribution 4.0 International License, which permits use, sharing, adaptation, distribution and reproduction in any medium or format, as long as you give appropriate credit to the original author(s) and the source, provide a link to the Creative Commons licence, and indicate if changes were made. The images or other third party material in this article are included in the article's Creative Commons licence, unless indicated otherwise in a credit line to the material. If material is not included in the article's Creative Commons licence and your intended use is not permitted by statutory regulation or exceeds the permitted use, you will need to obtain permission directly from the copyright holder. To view a copy of this licence, visit http://creativecommons.org/licenses/by/4.0/.

\section{References}

1. Gagner M, Lacroix A, Bolté E (1992) Laparoscopic adrenalectomy in Cushing's syndrome and pheochromocytoma. N Engl J Med 327(14):1033

2. Tsuru N, Suzuki K, Ushiyama T, Ozono S (2005) Laparoscopic adrenalectomy for large adrenal tumors. J Endourol 19(5):537-540

3. Telem DA, Nguyen SQ, Chin EH, Weber K, Divino CM (2009) Laparoscopic resection of giant adrenal cavernous hemangioma. JSLS 13(2):260-262

4. Heger P, Probst P, Hüttner FJ, Gooßen K, Proctor T, Müller-Stich BP, Strobel O, Büchler MW, Diener MK (2017) Evaluation of open and minimally invasive adrenalectomy: a systematic review and networkmeta-analysis. World J Surg 41(11):2746-2757. https ://doi.org/10.1007/s00268-017-4095-3

5. Hu X, Yang WX, Shao YX, Dou WC, Xiong SC, Li X (2020) Minimally invasive versus open adrenalectomy in patients with adrenocortical carcinoma: a meta-analysis. Ann Surg Oncol. https ://doi.org/10.1245/s10434-020-08454-1 (Epub ahead of print)

6. Calcatera NA, Hsiung-Wang C, Suss NR, Winchester DJ, MooYoung TA, Prinz RA (2018) Minimally invasive adrenalectomy for adrenocortical carcinoma: five-year trends and predictors of conversion. World J Surg. 42(2):473-481. https://doi.org/10.1007/ s00268-017-4290-2

7. Nomine-Criqui C, Germain A, Ayav A, Bresler L, Brunaud L (2017) Robot-assisted adrenalectomy: indications and drawbacks. Updates Surg 69(2):127-133. https://doi.org/10.1007/s13304-0170448-6 (Epub 2017 May 12)

8. Walz MK, Alesina PF, Wenger FA, Deligiannis A, Szuczik E, Petersenn S, Ommer A, Groeben H, Peitgen K, Janssen OE, Philipp T, Neumann HP, Schmid KW, Mann K (2006) Posterior retroperitoneoscopic adrenalectomy-results of 560 procedures in 520 patients. Surgery. 140(6):943-948 (discussion 948-50)

9. Berber E, Mitchell J, Milas M, Siperstein A (2010) Robotic posterior retroperitoneal adrenalectomy. Arch Surg 145(8):781-784. https://doi.org/10.1001/archsurg.2010.148

10. Lairmore TC, Folek J, Govednik CM, Snyder SK (2016) Improving minimally invasive adrenalectomy: selection of optimal approach and comparison of outcomes. World J Surg 40(7):16251631. https://doi.org/10.1007/s00268-016-3471-8

11. Piazza L, Caragliano P, Scardilli M, Sgroi AV, Marino G, Giannone G (1999) Laparoscopic robot-assisted right adrenalectomy and left ovariectomy (case reports). Chir Ital. 51(6):465-466

12. Economopoulos KP, Mylonas KS, Stamou AA, Theocharidis V, Sergentanis TN, Psaltopoulou T, Richards ML (2017) Laparoscopic versus robotic adrenalectomy: a comprehensive meta-analysis. Int J Surg 38:95-104. https://doi.org/10.1016/j. ijsu.2016.12.118 (Epub 2016 Dec 30)

13. Morris LF, Perrier ND (2012) Advances in robotic adrenalectomy. Curr Opin Oncol 24(1):1-6. https://doi.org/10.1097/CCO.0b013 e32834da8e1 
14. Tang K, Li H, Xia D, Yu G, Guo X, Guan W, Xu H, Ye Z (2015) Robot-assisted versus laparoscopic adrenalectomy: a systematic review and meta-analysis. J Laparoendosc Adv Surg Tech A 25(3):187-195. https://doi.org/10.1089/lap.2014.0431

15. Pahwa M (2017) Robot-assisted adrenalectomy: current perspectives. Robot Surg. 4:1-6. https://doi.org/10.2147/RSRR.S100887 (eCollection 2017)

16. Samreen S, Fluck M, Hunsinger M, Wild J, Shabahang M, Blansfield JA (2019) Laparoscopic versus robotic adrenalectomy: a review of the national inpatient sample. J Robot Surg 13(1):69-75. https://doi.org/10.1007/s11701-018-0808-3 (Epub 2018 Apr 25)

17. Patel AD, Oleynikov D (2017) The SAGES manual of robotic surgery. In: Saunders ND (ed) Robotic adrenalectomy. Springer, Cham, Switzerland, pp 227-238

18. Ludwig AT, Wagner KR, Lowry PS, Papaconstantinou HT, Lairmore TC (2010) Robot-assisted posterior retroperitoneoscopic adrenalectomy. J Endourol 24(8):1307-1314. https://doi. org/10.1089/end.2010.0152

19. Greilsamer T, Nomine-Criqui C, Thy M, Ullmann T, Zarnegar R, Bresler L, Brunaud L (2019) Robotic-assisted unilateral adrenalectomy: risk factors for perioperative complications in 303 consecutive patients. Surg Endosc 33(3):802-810. https://doi. org/10.1007/s00464-018-6346-2 (Epub 2018 Jul 11)

20. Morris L, Ituarte P, Zarnegar R, Duh QY, Ahmed L, Lee J, Inabnet W 3rd, Meyer-Rochow G, Sidhu S, Sywak M, Yeh M (2008) Laparoscopic adrenalectomy after prior abdominal surgery. World J Surg 32(5):897-903. https://doi.org/10.1007/s00268-007-9438-Z

21. Coste T, Caiazzo R, Torres F, Vantyghem MC, Carnaille B, Do Cao C, Douillard C, Pattou F (2017) Laparoscopic adrenalectomy by transabdominal lateral approach: 20 years of experience. Surg Endosc 31(7):2743-2751. https://doi.org/10.1007/s00464-0164830-0 (Epub 2016 Nov 10)

22. Gaujoux S, Bonnet S, Leconte M, Zohar S, Bertherat J, Bertagna X, Dousset B (2011) Risk factors for conversion and complications after unilateral laparoscopic adrenalectomy. Br J Surg 98(10):1392-1399. https://doi.org/10.1002/bjs.7558 (Epub 2011 May 25)

23. Perivoliotis K, Baloyiannis I, Sarakatsianou C, Tzovaras G (2020) Comparing the efficacy and safety of laparoscopic and robotic adrenalectomy: a meta-analysis and trial sequential analysis. Langenbecks Arch Surg. https:// doi.org/10.1007/s00423-020-01860-9 (Epub ahead of print)

24. Chai YJ, Kwon H, Yu HW, Kim SJ, Choi JY, Lee KE, Youn YK (2014) Systematic review of surgical approaches for adrenal tumors: lateral transperitoneal versus posterior retroperitoneal and laparoscopic versus robotic adrenalectomy. J Endocrinol. 2014:918346. https://doi.org/10.1155/2014/918346 (Epub 2014 Dec 17)

25. Nordenström E, Westerdahl J, Hallgrimsson P, Bergenfelz A (2011) A prospective study of 100 roboticallyassisted laparoscopic adrenalectomies. J Robot Surg 5(2):127-131. https://doi. org/10.1007/s11701-011-0243-1

26. Wu JC, Wu HS, Lin MS, Chou DA, Huang MH (2008) Comparison of robot-assisted laparoscopic adrenalectomy with traditional laparoscopic adrenalectomy-1 year follow-up. Surg Endosc 22(2):463-466 (Epub 2007 Aug 18)

27. Giulianotti PC, Buchs NC, Addeo P, Bianco FM, Ayloo SM, Caravaglios G, Coratti A (2011) Robot-assisted adrenalectomy: a technical option for the surgeon? Int J Med Robot 7(1):27-32. https://doi.org/10.1002/rcs.364 (Epub 2010 Nov 11)

28. Morino M, Benincà G, Giraudo G, Del Genio GM, Rebecchi F, Garrone C (2004) Robot-assisted vs laparoscopic adrenalectomy: a prospective randomized controlled trial. Surg Endosc 18(12):1742-1746 (Epub 2004 Oct 26)

29. Agrusa A, Romano G, Navarra G, Conzo G, Pantuso G, Buono GD, Citarrella R, Galia M, Monte AL, Cucinella G, Gulotta G
(2017) Innovation in endocrine surgery: robotic versus laparoscopic adrenalectomy. Meta-analysis and systematic literature review. Oncotarget 8(60):102392-102400. https://doi. org/10.18632/oncotarget.22059.eCollection2017Nov24

30. Brunaud L, Ayav A, Zarnegar R, Rouers A, Klein M, Boissel P, Bresler L (2008) Prospective evaluation of 100 robotic-assisted unilateral adrenalectomies. Surgery 144(6):995-1001. https://doi. org/10.1016/j.surg.2008.08.032 (discussion 1001)

31. Pineda-Solís K, Medina-Franco H, Heslin MJ (2013) Robotic versus laparoscopic adrenalectomy: a comparative study in a high-volume center. Surg Endosc 27(2):599-602. https://doi. org/10.1007/s00464-012-2496-9 (Epub 2012 Sep 7)

32. Fang AM, Rosen J, Saidian A, Bae S, Tanno FY, Chambo JL, Bloom J, Gordetsky J, Srougi V, Phillips J, Rais-Bahrami S (2020) Perioperative outcomes of laparoscopic, robotic, and open approaches to pheochromocytoma. J Robot Surg. https:// doi.org/10.1007/s11701-020-01056-9 (Epub ahead of print)

33. Karabulut K, Agcaoglu O, Aliyev S, Siperstein A, Berber E. Comparison of intraoperative time use and perioperative outcomes for robotic versus laparoscopic adrenalectomy. Surgery. 2012 Apr;151(4):537-42. https://doi.org/10.1016/j.surg.2011.09.047

34. Brandao LF, Autorino R, Zargar H, Krishnan J, Laydner H, Akca O, Mir MC, Samarasekera D, Stein R, Kaouk J (2014) Robotassisted laparoscopic adrenalectomy: step-by-step technique and comparative outcomes. Eur Urol 66(5):898-905. https://doi. org/10.1016/j.eururo.2014.04.003 (Epub 2014 May 13)

35. Agcaoglu O, Aliyev S, Karabulut K, Siperstein A, Berber E (2012) Robotic vs laparoscopic posterior retroperitoneal adrenalectomy. Arch Surg 147(3):272-275. https://doi.org/10.1001/archs urg.2011.2040

36. You JY, Lee HY, Son GS, Lee JB, Bae JW, Kim HY (2013) Comparison of robotic adrenalectomy with traditional laparoscopic adrenalectomy with a lateral transperitoneal approach: a singlesurgeon experience. Int J Med Robot 9(3):345-350. https://doi. org/10.1002/rcs.1497 (Epub 2013 May 2)

37. Aliyev S, Karabulut K, Agcaoglu O, Wolf K, Mitchell J, Siperstein A, Berber E (2013) Robotic versus laparoscopic adrenalectomy for pheochromocytoma. Ann Surg Oncol 20(13):4190-4194. https:// doi.org/10.1245/s10434-013-3134-z (Epub 2013 Jul 18)

38. D’Annibale A, Lucandri G, Monsellato I, De Angelis M, Pernazza G, Alfano G, Mazzocchi P, Pende V (2012) Robotic adrenalectomy: technical aspects, early results and learning curve. Int $\mathbf{J}$ Med Robot 8(4):483-490. https://doi.org/10.1002/rcs.1454 (Epub 2012 Oct 19)

39. Morelli L, Tartaglia D, Bronzoni J, Palmeri M, Guadagni S, Di Franco G, Gennai A, Bianchini M, Bastiani L, Moglia A, Ferrari V, Fommei E, Pietrabissa A, Di Candio G, Mosca F (2016) Robotic assisted versus pure laparoscopic surgery of the adrenal glands: a case-control study comparing surgical techniques. Langenbecks Arch Surg 401(7):999-1006 (Epub 2016 Aug 12)

40. Aksoy E, Taskin HE, Aliyev S, Mitchell J, Siperstein A, Berber E (2013) Robotic versus laparoscopic adrenalectomy in obese patients. Surg Endosc 27(4):1233-1236. https://doi.org/10.1007/ s00464-012-2580-1 (Epub 2012 Oct 17)

41. Teo XL, Lim SK (2016) Robotic assisted adrenalectomy: is it ready for prime time? Investig Clin Urol 57(Suppl 2):S130-S146 (Epub 2016 Nov 30)

42. Raffaelli M, Brunaud L, De Crea C, Hoche G, Oragano L, Bresler L, Bellantone R, Lombardi CP (2014) Synchronous bilateral adrenalectomy for Cushing's syndrome: laparoscopic versus posterior retroperitoneoscopic versus robotic approach. World J Surg 38(3):709-715. https://doi.org/10.1007/s00268-013-2326-9

43. Brandao LF, Autorino R, Laydner H, Haber GP, Ouzaid I, De Sio M, Perdonà S, Stein RJ, Porpiglia F, Kaouk JH (2014) Robotic versus laparoscopic adrenalectomy: a systematic review 
and meta-analysis. Eur Urol 65(6):1154-1161. https://doi. org/10.1016/j.eururo.2013.09.021 (Epub 2013 Sep 20)

44. Rothermel LD, Lipman JM (2016) Estimation of blood loss is inaccurate and unreliable. Surgery 160(4):946-953. https://doi. org/10.1016/j.surg.2016.06.006 (Epub 2016 Aug 17)

45. Remzi M (2016) Robotic surgery is unnecessary for adrenalectomy. Eur Urol Focus 1(3):261-262. https://doi.org/10.1016/j. euf.2015.03.005 (Epub 2015 Jul 14)

46. Taskin HE, Aliyev S, Aksoy E, Hamrahian A, Siperstein A, Berber E (2014) Bilateral posterior retroperitoneal robotic adrenalectomy for ACTH-independent Cushing syndrome. Surg Laparosc Endosc Percutan Tech 24(3):e113-e115. https://doi.org/10.1097/ SLE.0b013e31828fa7da

47. Takata MC, Kebebew E, Clark OH, Duh QY (2008) Laparoscopic bilateral adrenalectomy: results for 30 consecutive cases. Surg Endosc 22(1):202-207

48. Tuncel A, Langenhuijsen J, Erkan A, Mikhaylikov T, Arslan M, Aslan Y, Berker D, Ozgok Y, Gallyamov E, Gozen AS (2020) Comparison of synchronous bilateral transperitoneal and posterior retroperitoneal laparoscopic adrenalectomy: results of a multicenter study. Surg Endosc. https://doi.org/10.1007/s00464-02007474-y (Epub ahead of print)

49. Maker AV, Maker VK (2017) Techniques to perform robotic left adrenalectomy in the obese patient. Surg Endosc 1(2):950. https ://doi.org/10.1007/s00464-016-5049-9 (Epub 2016 Jul 7)

50. Brunaud L, Bresler L, Ayav A, Zarnegar R, Raphoz AL, Levan T, Weryha G, Boissel P (2008) Robotic-assisted adrenalectomy: what advantages compared to lateral transperitoneal laparoscopic adrenalectomy? Am J Surg 195(4):433-438. https://doi. org/10.1016/j.amjsurg.2007.04.016

51. Pędziwiatr M, Major P, Pisarska M, Natkaniec M, Godlewska M, Przęczek K, Dworak J, Dembiński M, Zub-Pokrowiecka A, Budzyński A (2017) Laparoscopic transperitoneal adrenalectomy in morbidly obese patients is not associated with worse short-term outcomes. Int J Urol 24(1):59-63. https://doi. org/10.1111/iju.13241 (Epub 2016 Oct 12)

52. Agcaoglu O, Akbas M, Ozdemir M, Makay O (2019) The impact of body mass index on perioperative outcomes of robotic adrenalectomy: an update. Surg Innov 26(6):687-691. https:// doi.org/10.1177/1553350619858854 (Epub 2019 Jun 27)

53. Feo CV, Portinari M, Maestroni U, Del Rio P, Severi S, Viani L, Pravisani R, Soliani G, Zatelli MC, Ambrosio MR, Tong J, Terrosu G, Bresadola V (2016) Applicability of laparoscopic approach to the resection of large adrenal tumours: a retrospective cohort study on 200 patients. Surg Endosc 30(8):35323540. https://doi.org/10.1007/s00464-015-4643-6 (Epub 2015 Nov 5)

54. Agcaoglu O, Aliyev S, Karabulut K, Mitchell J, Siperstein A, Berber E (2012) Robotic versus laparoscopic resection of large adrenal tumors. Ann Surg Oncol 19(7):2288-2294. https://doi. org/10.1245/s10434-012-2296-4 (Epub 2012 Mar 7)

55. Quadri P, Esposito S, Coleoglou A, Danielson KK, Masrur M, Giulianotti PC (2019) Robotic adrenalectomy: are we expanding the indications of minimally invasive surgery? J Laparoendosc Adv Surg Tech A 29(1):19-23. https://doi.org/10.1089/ lap.2018.0286 (Epub 2018 Sep 28)

56. Thompson LH, Nordenström E, Almquist M, Jacobsson H, Bergenfelz A (2017) Risk factors for complications after adrenalectomy: results from a comprehensive national database. Langenbecks Arch Surg 402(2):315-322. https://doi.org/10.1007/s0042 3-016-1535-8 (Epub 2016 Nov 28)

57. Hemal AK, Singh A, Gupta NP (2008) Whether adrenal mass more than $5 \mathrm{~cm}$ can pose problem in laparoscopic adrenalectomy? An evaluation of 22 patients. World J Urol 26(5):505-508. https ://doi.org/10.1007/s00345-008-0270-3 (Epub 2008 Jun 7)
58. Conzo G, Tartaglia E, Gambardella C, Esposito D, Sciascia V, Mauriello C, Nunziata A, Siciliano G, Izzo G, Cavallo F, Thomas G, Musella M, Santini L (2016) Minimally invasive approach for adrenal lesions: systematic review of laparoscopic versus retroperitoneoscopic adrenalectomy and assessment of risk factors for complications. Int J Surg 28(Suppl 1):S118-S123. https://doi. org/10.1016/j.ijsu.2015.12.042 (Epub 2015 Dec 18)

59. Ye C, Yang Y, Guo F, Wang F, Zhang C, Yang B (2019) Robotic enucleation of adrenal masses: technique and outcomes. World J Urol. https://doi.org/10.1007/s00345-019-02868-7 (Epub ahead of print)

60. Kaye DR, Storey BB, Pacak K, Pinto PA, Linehan WM, Bratslavsky G (2010) Partial adrenalectomy: an underutilized first line therapy for small adrenal tumors. J Urol 184(1):18-25. https://doi. org/10.1016/j.juro.2010.03.052 (Author manuscript; available in PMC 2011 Sep 1. Published in final edited form as: J Urol)

61. St Julien J, Ball D, Schulick R (2006) Robot-assisted corticalsparing adrenalectomy in a patient with Von Hippel-Lindau disease and bilateral pheochromocytomas separated by 9 years. J Laparoendosc Adv Surg Tech A 16(5):473-477

62. Asher KP, Gupta GN, Boris RS, Pinto PA, Linehan WM, Bratslavsky G (2011) Robot-assisted laparoscopic partial adrenalectomy for pheochromocytoma: the national cancer institute technique. Eur Urol 60(1):118-124. https://doi.org/10.1016/j.eurur o.2011.03.046 (Epub 2011 Apr 9)

63. Boris RS, Gupta G, Linehan WM, Pinto PA, Bratslavsky G (2011) Robot assisted laparoscopic partial adrenalectomy: initial experience. Urology 77(4):775-780. https://doi.org/10.1016/j.urolo gy.2010.07.501 (Epub 2010 Dec 3)

64. Simone G, Anceschi U, Tuderti G, Misuraca L, Celia A, De Concilio B, Costantini M, Stigliano A, Minisola F, Ferriero M, Guaglianone S, Gallucci M (2019) Robot-assisted partial adrenalectomy for the treatment of conn's syndrome: surgical technique, and perioperative and functional outcomes. Eur Urol 75(5):811816. https://doi.org/10.1016/j.eururo.2018.07.030 (Epub 2018 Aug 1)

65. Gupta NP, Nayyar R, Singh P, Anand A (2010) Robot-assisted adrenal-sparing surgery for pheochromocytoma: initial experience. J Endourol 24(6):981-985. https://doi.org/10.1089/ end.2009.0351

66. Koehne EL, Bajic P, Gupta GN (2019) Robotic-assisted laparoscopic retroperitoneal adrenalectomy. Surg Oncol 31:7. https:// doi.org/10.1016/j.suronc.2019.06.005 (Epub 2019 Jun 22)

67. Pavan N, Autorino R, Lee H, Porpiglia F, Sun Y, Greco F, Jeff Chueh S, Han DH, Cindolo L, Ferro M, Chen X, Branco A, Fornara P, Liao CH, Miyajima A, Kyriazis I, Puglisi M, Fiori C, Yang B, Fei G, Altieri V, Jeong BC, Berardinelli F, Schips L, De Cobelli O, Chen Z, Haber GP, He Y, Oya M, Liatsikos E, Brandao L, Challacombe B, Kaouk J, Darweesh I (2016) Impact of novel techniques on minimally invasive adrenal surgery: trends and outcomes from a contemporary international large series in urology. World J Urol 34(10):1473-1479. https://doi.org/10.1007/s0034 5-016-1791-9 (Epub 2016 Feb 29)

68. Arghami A, Dy BM, Bingener J, Osborn J, Richards ML (2015) Single-port robotic-assisted adrenalectomy: feasibility, safety, and cost-effectiveness. JSLS 19(1):e2014.00218. https://doi. org/10.4293/JSLS.2014.00218

69. Lee GS, Arghami A, Dy BM, McKenzie TJ, Thompson GB, Richards ML (2016) Robotic single-site adrenalectomy. Surg Endosc 30(8):3351-3356. https://doi.org/10.1007/s00464-015-4611-1 (Epub 2015 Oct 20)

70. Park JH, Kim SY, Lee CR, Park S, Jeong JS, Kang SW, Jeong JJ, Nam KH, Chung WY, Park CS (2013) Robot-assisted posterior retroperitoneoscopic adrenalectomy using single-port access: technical feasibility and preliminary results. Ann Surg Oncol 
20(8):2741-2745. https://doi.org/10.1245/s10434-013-2891-z (Epub 2013 Mar 14)

71. Wang L, Wu Z, Li M, Cai C, Liu B, Yang Q, Sun Y (2013) Laparoendoscopic single-site adrenalectomy versus conventional laparoscopic surgery: a systematic review and meta-analysis of observational studies. J Endourol 27(6):743-750. https://doi. org/10.1089/end.2012.0599 (Epub 2013 Apr 23)

72. Colvin J, Zaidi N, Berber E (2016) The utility of indocyanine green fluorescence imaging during robotic adrenalectomy. J Surg Oncol 114(2):153-156. https://doi.org/10.1002/jso.24296 (Epub 2016 May 18)

73. Manny T, Pompeo A, Hemal A (2013) Robotic partial adrenalectomy using indocyanine green dye with near-infrared imaging: the initial clinical experience. Urology 82:738-742

74. Moore EC, Berber E (2019) Fluorescence techniques in adrenal surgery. Gland Surg 8(Suppl 1):S22-S27. https://doi.org/10.21037 Igs.2019.03.01

75. Lerchenberger M, Gündogar U, Al Arabi N, Gallwas JKS, Stepp H, Hallfeldt KKJ, Ladurner R (2020) Indocyanine green fluorescence imaging during partial adrenalectomy. Surg Endosc 34(5):2050-2055. https://doi.org/10.1007/s00464-019-06985-7 (Epub 2019 Jul 24)

76. Kahramangil B, Kose E, Berber E (2018) Characterization of fluorescence patterns exhibited by different adrenal tumors: determining the indications for indocyanine green use in adrenalectomy. Surgery 164(5):972-977. https://doi.org/10.1016/j. surg.2018.06.012 (Epub 2018 Aug 4)

77. Sound S, Okoh AK, Bucak E, Yigitbas H, Dural C, Berber E (2016) Intraoperative tumor localization and tissue distinction during robotic adrenalectomy using indocyanine green fluorescence imaging: a feasibility study. Surg Endosc 30(2):657-662. https://doi.org/10.1007/s00464-015-4256-0 (Epub 2015 Jul 22)

78. Winter JM, Talamini MA, Stanfield CL, Chang DC, Hundt JD, Dackiw AP, Campbell KA, Schulick RD (2006) Thirty robotic adrenalectomies: a single institution's experience. Surg Endosc 20(1):119-124 (Epub 2005 Dec 7)

79. Probst KA, Ohlmann CH, Saar M, Siemer S, Stöeckle M, Janssen M (2016) Robot-assisted vs open adrenalectomy: evaluation of cost-effectiveness and peri-operative outcome. BJU Int 118(6):952-957. https://doi.org/10.1111/bju.13529 (Epub 2016 Jun 10)

80. Feng Z, Feng MP, Feng DP, Rice MJ, Solórzano CC (2018) A cost-conscious approach to robotic adrenalectomy. J Robot Surg 12(4):607-611. https://doi.org/10.1007/s11701-018-0782-9 (Epub 2018 Jan 31)

81. Barbash GI, Glied SA (2010) New technology and health care costs-the case of robot-assisted surgery. N Engl J Med 363(8):701-704. https://doi.org/10.1056/NEJMp1006602

82. Raman SR, Shakov E, Carnevale N, Yiengpruksawan A (2012) Robotic adrenalectomy by an open surgeon: are outcomes different? J Robot Surg 6(3):207-212. https://doi.org/10.1007/s1170 1-011-0292-5 (Epub 2011 Jul 8)

83. Pahwa M, Pahwa AR, Batra R, Abraham RR, Chawla A, Kathuria S, Sharma A (2015) Robotic assisted laparoscopic adrenalectomy: initial experience from a tertiary care centre in India. J
Minim Access Surg 11(1):83-86. https://doi.org/10.4103/09729941.147704

84. Undre S, Munz Y, Moorthy K, Martin S, Rockall T, Vale J, Darzi A (2004) Robot-assisted laparoscopic adrenalectomy: preliminary UK results. BJU Int 93(3):357-359

85. Bentas W, Wolfram M, Bräutigam R, Binder J (2002) Laparoscopic transperitoneal adrenalectomy using a remote-controlled robotic surgical system. J Endourol 16(6):373-376

86. Krane LS, Shrivastava A, Eun D, Narra V, Bhandari M, Menon M (2008) A four-step technique of robotic right adrenalectomy: initial experience. BJU Int 101(10):1289-1292. https://doi. org/10.1111/j.1464-410X.2008.07433.x (Epub 2008 Feb 15)

87. Akarsu C, Dural AC, Kankaya B, Çelik MF, Köneş O, Mert M, Kalaycı MU, Alış H (2014) The early results of our initial experience with robotic adrenalectomy. Ulus Cerrahi Derg. 30(1):28-33. https://doi.org/10.5152/UCD.2014.2518 (eCollection 2014)

88. Desai MM, Gill IS, Kaouk JH, Matin SF, Sung GT, Bravo EL (2002) Robotic-assisted laparoscopic adrenalectomy. Urology 60(6):1104-1107

89. Kahramangil B, Berber E (2018) Comparison of posterior retroperitoneal and transabdominal lateral approaches in robotic adrenalectomy: an analysis of 200 cases. Surg Endosc 32(4):19841989. https://doi.org/10.1007/s00464-017-5894-1 (Epub 2017 Oct 19)

90. Feng Z, Feng MP, Levine JW, Solórzano CC (2017) Robotic retroperitoneoscopic adrenalectomy: useful modifications of the described posterior approach. J Robot Surg 11(4):409-414. https ://doi.org/10.1007/s11701-016-0671-z (Epub 2017 Jan 2)

91. Kim WW, Lee YM, Chung KW, Hong SJ, Sung TY (2019) Safety and feasibility of reduced-port site surgery for robotic posterior retroperitoneal adrenalectomy. Surg Endosc. https:// doi.org/10.1007/s00464-019-07273-0 (Epub ahead of print)

92. Makay O, Erol V, Ozdemir M (2019) Robotic adrenalectomy. Gland Surg 8(Suppl 1):S10-S16. https://doi.org/10.21037/ gs.2019.01.09

93. Colvin J, Krishnamurthy V, Jin J, Shin J, Siperstein A, Berber E (2017) A comparison of robotic versus laparoscopic adrenalectomy in patients with primary hyperaldosteronism. Surg Laparosc Endosc Percutan Tech 27(5):391-393. https://doi.org/10.1097/ SLE.0000000000000455

94. Feng Z, Feng MP, Feng DP, Solórzano CC (2020) Roboticassisted adrenalectomy using da Vinci Xi vs. Si: are there differences? J Robot Surg. 14(2):349-355. https://doi.org/10.1007/ s11701-019-00995-2 (Epub 2019 Jul 4)

95. Choi KH, Ham WS, Rha KH, Lee JW, Jeon HG, Arkoncel FR, Yang SC, Han WK (2011) Laparoendoscopic single-site surgeries: a single-center experience of 171 consecutive cases. Korean J Urol 52(1):31-38. https://doi.org/10.4111/kju.2011.52.1.31 (Epub 2011 Jan 24)

Publisher's Note Springer Nature remains neutral with regard to jurisdictional claims in published maps and institutional affiliations. 